\title{
Variation in Morphological and Physiological Characteristics of Wild Elymus nutans Ecotypes from Different Altitudes in the Northeastern Tibetan Plateau
}

\author{
Juan Qi ${ }^{1},{ }^{1}$ Wenhui Liu, ${ }^{2}$ Ting Jiao, ${ }^{1}$ and Ann Hamblin ${ }^{3}$ \\ ${ }^{1}$ Key Laboratory of Grassland Ecosystem of Ministry of Education, College of Grassland Science, Gansu Agricultural University, \\ Lanzhou, 730070 Gansu, China \\ ${ }^{2}$ Key Laboratory of Superior Forage Germplasm in the Qinghai-Tibetan Plateau, Qinghai Academy of Animal Science and \\ Veterinary Medicine, Xining, 810016 Qinghai, China \\ ${ }^{3}$ School of Agriculture and Environment, The University of Western Australia, Perth WA 6009, Australia
}

Correspondence should be addressed to Juan Qi; qijuan0622@163.com

Received 26 September 2019; Revised 27 November 2019; Accepted 13 December 2019; Published 11 January 2020

Guest Editor: Yuan Li

Copyright ( 2020 Juan Qi et al. This is an open access article distributed under the Creative Commons Attribution License, which permits unrestricted use, distribution, and reproduction in any medium, provided the original work is properly cited.

\begin{abstract}
The availability of suitable native plant species for local animal husbandry development and ecological restoration is limited on the Qinghai-Tibetan Plateau. Therefore, comparisons of the ecological adaptability of native species to alternative habitats and their introduction into new habitats are of high importance. This study is aimed at identifying the alteration in morphological and physiological characteristics by measuring photosynthetic physiology, nutrient content, and growth associated with adaptation of plants to conditions at different altitudes 2450, 2950, 3100, and $3300 \mathrm{~m}$ above sea level (a. s. 1.) on the plateau. Seeds of the dominant grass, Elymus nutans, were collected from locations at these altitudes and grown at a test location of $2950 \mathrm{~m}$ a. $\mathrm{s} .1$. Results indicated that altitude had no significant effect on plant height and root depth. However, the leaf area and total root surface area of plants derived from 2950 and $3300 \mathrm{~m}$ a. s. l. showed a parabolic response, being greater than those of plants derived from the lowest $(2450 \mathrm{~m})$ and highest $(3300 \mathrm{~m}$ a. s. 1.). Total (root plus shoot) dry matter reduced progressively from 2450 to $3300 \mathrm{~m}$ a. s. 1, while root: shoot ratio increased progressively with altitude. Seed yield of plants originating from the test altitude $(2950 \mathrm{~m}$ a. s. l) was significantly higher than at any other altitude, being $20 \%$ lower at $2450 \mathrm{~m}$, and $38 \%$ and $58 \%$ less in populations originating from the higher altitudes $(3100$ and $3300 \mathrm{~m}$ a. s. 1.). There was also a parabolic decline in response of Elymus nutans germplasm from 3100,3300 , and $2450 \mathrm{~m}$, compared with plants from $2950 \mathrm{~m}$ a. s. 1., to photosynthetic rate, total $\mathrm{N}$, soluble sugar, and starch contents. Germplasm from $2450 \mathrm{~m}$ a. s. l. had significantly lower shoot and higher root carbon content, lower shoot nitrogen, and lower root carbon-to-nitrogen ratio compared with plants derived from the other three altitudes. It is suggested that the stable, genetically determined morphological and physiological features of ecotypes showed parabolic responses which means these ecotypes have become adapted to local habitats, whereas parameters such as dry matter, total root: shoot ratio, photosynthetic rate, and intercellular $\mathrm{CO}_{2}$ concentration of plants reflected phenotypic linear response to current abiotic conditions. It is postulated that introduced ecotypes from 2450, 3100, and $3300 \mathrm{~m}$ could adapt to the environment at $2950 \mathrm{~m}$ a. s. l. gradually. We conclude that the increased thermal regime experienced by plants introduced from high altitude to low altitude may facilitate the increased growth of Elymus nutans subtypes. It is important to preserve local strains of native species, or ecotypes, for reintroduction into degraded environments and to maintain the greatest ecosystem stability in the northeastern Tibetan Plateau.
\end{abstract}

\section{Introduction}

Plants have the ability to alter their morphological and physiological traits in response to environmental variations
$[1,2]$ and adjust the expression of these traits to accommodate their adaptability across multiple environments [3]. Altitude can significantly influence plant growth, structure, function, and metabolism $[4,5]$. The morphological and 
physiological characteristics of alpine species reflect their environmental adaption under certain altitudinal gradients [6]. As a consequence, modern plant ecologists have paid much attention to these plant characteristics in different biological and ecological zones to better understand their adaptive mechanisms $[7,8]$.

Alpine plants exhibit specific morphological, physiological, and biochemical responses to an increasing altitude, such as size and increases in the leaf thickness [9-11]. Decreases in plant growth and a higher proportion of plant biomass in the roots usually result in a higher leaf $\mathrm{N}$ content and lower $\mathrm{C}: \mathrm{N}$ ratio, which lead to a higher photosynthetic capacity in alpine plants [12]. Moreover, the relationship between plant functional traits and environmental factors has been recently gaining increasing attention. Plant species may have an optimum altitude for production of biomass and net photosynthetic rate; their enzymatic activities can increase or decrease upon deviation from this optimum altitude [13-15]. Grasses exposed to high altitudinal areas with extreme climatic factors (cold, frost, drought, salinity, low oxygen, high wind velocity, intense UV radiation, and geographical differentiation) provide opportunities to study such adaptive mechanisms $[16,17]$. However, the adaptation mechanism in response to altitude variation and climate change is largely unknown [18].

Elymus nutans is a native perennial grass and plays an important ecological role in maintaining regional species diversity and ecosystem stability. It grows extensively across the Qinghai-Tibetan Plateau and Xinjiang of Northwestern China where it is well adapted to a range of environments and is extensively grazed by livestock $[19,20]$. It is also one of the important pasture species sown to increase livestock production and groundcover by perennial species. However, research on the species is not equal to the scale of its resource utilization in China. Most reports [21-24] have focused on the biology, genetic diversity, nutrition value, and yield of the species, but there has been little information on the morphological and physiological characteristics of E. nutans and the species' local adaptation to variations in altitude $[25,26]$. An understanding of these characteristics, particularly of the plant morphological attributes and variations in photosynthesis, is essential to help identify the mechanism of plant adaptability to local-scale environments. Our basic question was whether the physiological and ecological traits of plants of the same species grown in different habitats differed in their responses when grown in alternative environments and how they adapted to their new environment. We hypothesized that there was a set of significant differences in plant morphological, physiological, and biochemical responses of E. nutans to increasing altitude that could be taken as a surrogate for differences in thermal regime, solar radiation, and precipitation. Basing on previous work, we attempted to answer the following questions:

(1) How do the plant functional traits, photosynthesis, and dry matter respond to altitudinal variation
(2) What are the differences in physiological plasticity of the different physiological parameters of E. nutans in the alpine area

We selected changes in shoot and root length, leaf area and root area, dry matter and seed yield, soluble matter concentration, the ratio of carbon and nitrogen, and photosynthetic parameters to elucidate the ecophysiological processes. Because these processes may enable this plant to adapt to varying environments, we could use them to evaluate the potential of this species expanding into higher altitudes. It is expected that findings from this study will help to identify traits for plant breeding strains of $E$. nutans that may be increasingly adapted to climatically changing habitats and for the development of the management strategies to rehabilitate degraded pastures both for pastoral grazing production and environmental sustainability.

\section{Materials and Methods}

2.1. Experimental Material. Healthy E. nutans seeds were obtained from wild plants growing in Tianzhu county of Eastern Qilian Mountains $\left(102^{\circ} 23 \sim 102^{\circ} 78^{\prime}\right.$ E, $37^{\circ} 11 \sim 37^{\circ} 18^{\prime}$ $\mathrm{N})$, Qilian Mountains, China, which lies in the northeast margin of the Tibetan Plateau, a key site to understanding the species' adaptation in the northeastern of Tibetan Plateau. At least 15 plants of Elymus nutans per site were cut from four sites (Dachaigou, Jinqianghe, Honggeda, Daiqian) selected randomly from habitats at 2450, 2950, 3100, and $3300 \mathrm{~m}$ a. s. 1 , in an area of $100-1000 \mathrm{~m}^{2}$ that was ecologically homogeneous for the target ecotypes (see Figure 1).

The vegetation type in the sampling areas was composed of alpine meadow grasses and forbs. The soils on which each ecotype grew were of the same soil taxonomic category being shallow, postglacial subalpine meadow soils of high organic matter content. Livestock grazing is the only land use. Elymus nutans is the dominant species in this area and occurs naturally and abundantly at altitudes between 2000 and $5000 \mathrm{~m}$ a. s. 1. in the Qinghai-Tibetan Plateau. After collection, the samples were bulked, dried to $30^{\circ} \mathrm{C}$, and seeds threshed out. Seeds were stored at a constant $4^{\circ} \mathrm{C}$ temperature at the Seed Centre of the College of Grassland Science, Gansu Agricultural University, Lanzhou, China.

2.2. Site, Climate, and Design. Seeds of the 4 ecotypes were sown at the Tianzhu Alpine Grassland Experimental Station of Gansu Agricultural University at an altitude of $2950 \mathrm{~m}$ a. s. 1., the northeastern margin of the Qinghai-Tibetan Plateau, China. The climate is alpine, cold, and semiarid, with thin air and low temperature, and strong solar radiation, where there is no frost-free season, only cold and cool seasons. The annual average temperature is $0.1^{\circ} \mathrm{C}$, with the highest average temperature in July (mean $12.7^{\circ} \mathrm{C}$ ) and the lowest in January (mean $-18.3^{\circ} \mathrm{C}$ ). The average annual precipitation is $328.7 \mathrm{~mm}$, concentrated from June to September. The 4 ecotypes were sown as a randomized complete block design with 3 replicates and the plot size was $2 \mathrm{~m} \times 5 \mathrm{~m}=10 \mathrm{~m}^{2}$ with a $1 \mathrm{~m}$ gap between plots. Each plot has row spacing of $40 \mathrm{~cm}$. Sowing depth was $3-4 \mathrm{~cm}$ and sowing rate was $22.5 \mathrm{~kg} / \mathrm{ha}$. 


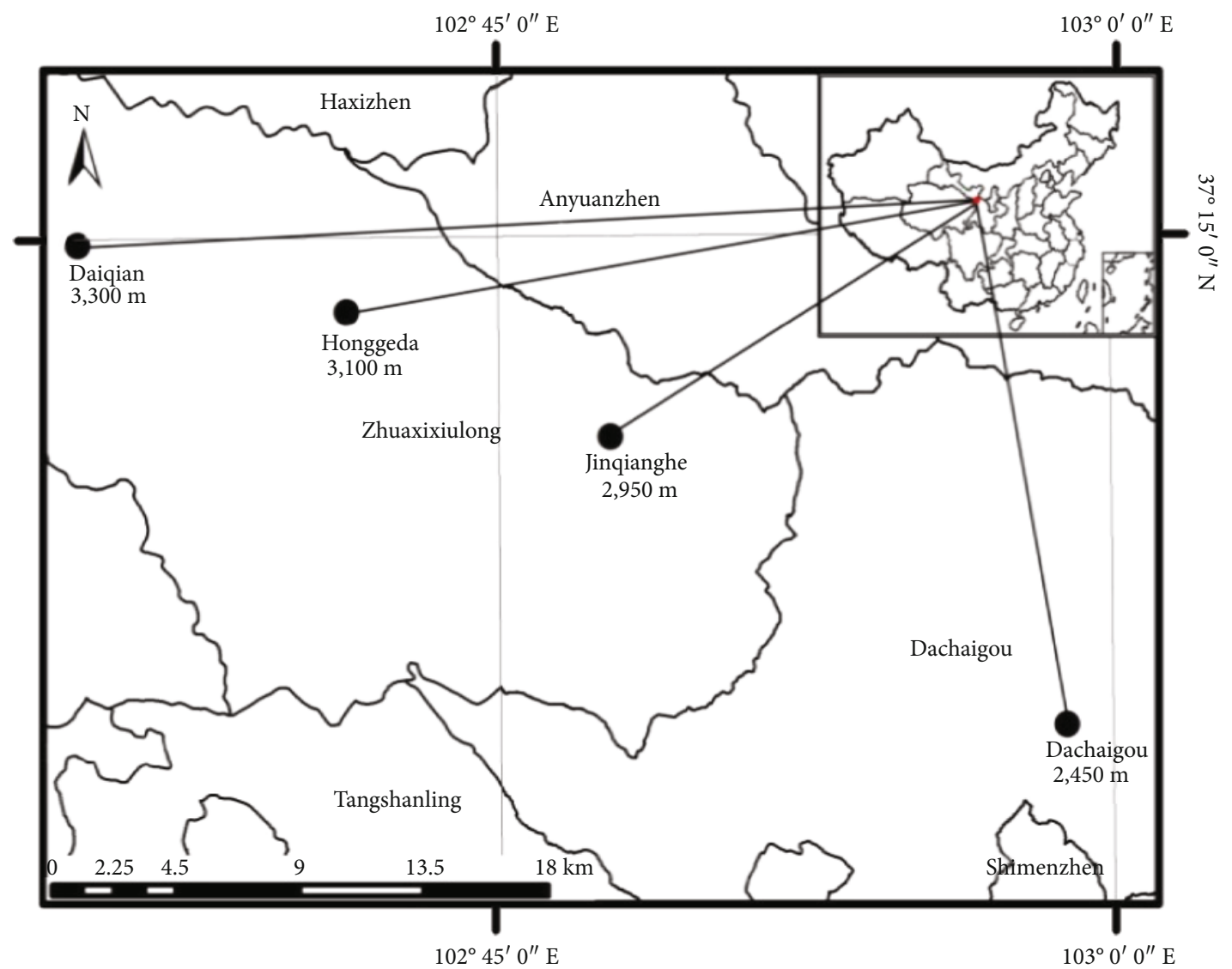

Figure 1: Sampling sites (dark spots) for Elumus nutans along eastern boundary Qilian Mountains in the Qinghai-Tibet Plateau.

The soil was a shallow, postglacial, subalpine scrub grassland soil with a higher organic matter content $(9.45 \%)$ in the $0 \sim 20 \mathrm{~cm}$ soil layer.

\subsection{Measurements}

2.3.1. Plant Height and Root Depth, Root Surface Area, and Volume. Establishment and vegetative growth of E. nutans is slow at altitudes above $2000 \mathrm{~m}$ a. s. 1., and plants only reach flowering and maturity by the second year. The first year's shoots die back and the growing points lie below the soil surface during the first winter, to reemerge in the second spring [27]. Therefore, all the data presented are from the second year of planting.

Selected measurements were made at different development stages. The plant morphological parameters (shoot height, root length, surface area, and volume) were measured during the period of rapid shoot extension in the second year (the end of July), flag leaf area was measured at full emergence of the flag leaf before flowering (the early of August), and the physiological parameters (soluble sugars, starch, total carbon and nitrogen, and gas exchange properties) and total aboveground (shoot) and belowground (root) dry matter were measured at flowering (August $10^{\text {th }}$ ).

Plant height was measured by recording the height of 20 randomly selected plants of $E$. nutans within a plot before each harvest with a $2 \mathrm{~m}$ ruler from the soil surface to the highest point of the plant and averaged to give the mean for each treatment plot. Sections of rows $33 \mathrm{~cm}$ long were then randomly selected, whole plants were dug out, and root depth was measured. Whole plants were stored in the selfsealing, labeled bags and refrigerated. Cleaned roots were put into the root plate submerging the root system, and root surface areas and root volume were measured using Photo Scanner and the data analyzed by Root Analysis software.

2.3.2. Leaf Areas. The areas of 10 flag leaves from randomly selected plants taken when flag leaves had fully emerged, and at flowering were determined using an AM-300 Area Meter (Analytical Development Company, Herts, UK).

2.3.3. Herbage Yield. Individual treatment plots were harvested for herbage yield at fully flowering period, with subsamples then taken from each plot, freshly weighed and oven dried at $65^{\circ} \mathrm{C}$ for 48 hours before being ground.

2.3.4. Seed Yield. Seed yield was made at $80 \%$ seed maturity (seeds drop easily) in mid-September. Seed collection was carried out from randomly selected plots of each ecotype, and the seed yield of each experimental plot $\left(10 \mathrm{~m}^{2}\right)$ was determined and converted into $\mathrm{kg} / \mathrm{ha}$.

2.3.5. Total Soluble Sugar. The physiological traits were all measured when plants were flowering. Soluble sugar was extracted from a $0.05 \mathrm{~g}$ sample with $1-4 \mathrm{ml} 80 \%(v / v)$ aqueous 
ethanol in a water bath at $80^{\circ} \mathrm{C}$ for $40 \mathrm{~min}$. This sample was centrifuged for 30 minutes at $12000 \mathrm{r} / \mathrm{min}$ the supernatant collected, the residue reextracted with $80 \%(v / v)$ aqueous ethanol, and finally, the sample was centrifuged and merged with the supernatant. The extracted solution was diluted to $50 \mathrm{ml}$ after extracting 2 times. $1 \mathrm{ml}$ of the extract obtained was mixed with $5 \mathrm{ml}$ of anthrone-sulphuric acid reagent. After cooling to room temperature, the absorbance was measured at $627 \mathrm{~nm}$ using a UV-2550 UV-visible spectrophotometer.

2.3.6. Starch Contents. The residue from the soluble sugars was boiled with $6 \mathrm{~mol} / \mathrm{l} \mathrm{HCl}$ in a water bath at $80^{\circ} \mathrm{C}$ for $5 \mathrm{~min}$, the sample centrifuged for 10 minutes at $4000 \mathrm{r} / \mathrm{min}$ the supernatant collected, and the above step repeated twice. Absorbance was measured at $580 \mathrm{~nm}$ using a UV-2550 UVvisible spectrophotometer. Starch content was calculated by multiplying by the coefficient of hydrolysis (0.9).

2.3.7. Determination of Total Organic Carbon Content. The samples were air-dried and ground to pass a $0.25 \mathrm{~mm}$ mesh for total organic carbon content. Approximately 0.015$0.020 \mathrm{~g}$ of each leaf and root sample was put into clear flask, mixed with $10 \mathrm{ml}$ of $\mathrm{K}_{2} \mathrm{Cr}_{2} \mathrm{O}_{7}$, and then heated $5 \mathrm{~min}$. The solution was cooled and then titrated with $\mathrm{FeSO}_{4}$ [28].

2.3.8. Nitrogen Analysis. N was determined by a small-scale Kjeldahl digestion [29]. $0.5 \mathrm{~g}$ of ground herbage from each sample was added to a flask, with $10 \mathrm{ml}$ of $\mathrm{H}_{2} \mathrm{SO}_{4}$ and $3 \mathrm{~g}$ of $\mathrm{CuSO}_{4} \cdot 5 \mathrm{H}_{2} \mathrm{O}$ and $\mathrm{K}_{2} \mathrm{SO}_{4}\left(\mathrm{CuSO}_{4} \cdot 5 \mathrm{H}_{2} \mathrm{O}: \mathrm{K}_{2} \mathrm{SO}_{4}=1: 10\right)$, and shaken until thoroughly mixed, heated from a low to high flame until the solution became clear, topped up to $100 \mathrm{ml}$ with ammonium-free distilled water, and $10 \mathrm{ml}$ of the solution mixed with $4 \mathrm{ml} 40 \% \mathrm{NaOH}$ and distilled using a Kjeldahl apparatus for $4 \mathrm{~min}$. $\mathrm{NH}_{3}$ released through distillation was absorbed by $1 \%$ boric acid and then titrated against $0.02 \mathrm{moll}^{-1} \mathrm{HCl}$ to determine the $\mathrm{N}$ content.

2.3.9. Gas Exchange. The Li-6400 portable photosynthetic analyzer (Li-COR, USA) was used to determine the daily change (8:30 am-17:30 pm) of photosynthetic parameters of E. nutans in an open gas analysis system. All measurements were carried out on healthy leaves in the field on sunny days at flowering period. Three leaves from each plot were randomly selected. The photosynthetic parameters included a net photosynthesis rate $\left(\mathrm{Pn}, \mathrm{mmol} \mathrm{CO}_{2} \mathrm{~m}^{-2} \mathrm{~s}^{-1}\right)$, transpira-

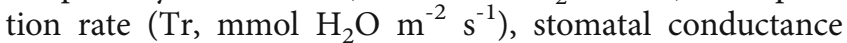
(Cond, $\mathrm{mmol} \mathrm{m}^{-2} \mathrm{~s}^{-1}$ ), and intercellular $\mathrm{CO}_{2}$ concentration $\left(\mathrm{Ci}, \mu \mathrm{mol} \mathrm{CO}_{2}\right.$ mol air $\left.{ }^{-1}\right)$. The parameters were calculated as the mean value for the day.

2.3.10. Statistical Analyses. Normality of distribution and homogeneity of variance were checked before any further statistical analysis. An investigation into normality of the data was carried out by performing the KolmogorovSmirnov test using SPSS 19 software. The data were normally distributed and better meet the assumptions of the statistical tests used. Analysis of variance and calculation of means were conducted using Excel and SPSS19 software. Morphological data and photosynthetic responses of plant were analyzed using a one-way analysis of variance (ANOVA), and the mean values were compared using the least significant difference (LSD) at $P=0.05$.

\section{Results}

3.1. Changes in the Plant Height and Root Depth of Four E. nutans Populations from Different Altitudes. The plants originating from different altitudes showed no statistically significant differences in height and root depth when grown at $2950 \mathrm{~m}$ a. s. 1. (Figure 2), which indicated that the altitude variations had less effect on the growth of plant height and root depth in alpine zone.

3.2. Changes in Leaf and Root Surface Area. Leaf and root area responses varied significantly along the altitudinal gradient, increasing from 2450 to $2950 \mathrm{~m}$ and then decreasing from 2950 to $3300 \mathrm{~m}$ a. s. 1 . Both of leaf areas and root surface areas were significantly different and smaller in value for plants collected from both the highest and lowest altitudes compared with those from 2950 and $3100 \mathrm{~m}$ a. s. 1 . (Figure 3). The leaf area and root surface area showed a significant negative correlation with altitude, and the correlation coefficient was 0.9938 and 0.9393 , respectively.

3.3. Changes in Total Root Length and Root Volume. Original altitude significantly influenced total root length and root volume but to different extents (Figure 4). There was no significant difference in total root length from 2450 to $2950 \mathrm{~m}$ but root length decreased as altitude increased from 2950 to $3300 \mathrm{~m}$ a. s. 1 . The root length from $3300 \mathrm{~m}$ was lower than that from $2450 \mathrm{~m}$ and $2950 \mathrm{~m}$ a. s. $1.41 \%$ and $46 \%$, respectively. Root volume increased as altitude increased from $2450 \mathrm{~m}$ to $2950 \mathrm{~m}$ a. s. 1 . and then decreased. The root volume from $3300 \mathrm{~m}$ was lower than that from $2950 \mathrm{~m}$ a. s. $1.47 \%$.

Figures 3 and 4 show that the smaller leaf areas and root characteristics of plants from the lowest altitude ( $2450 \mathrm{~m}$ a. s. 1.) when grown at higher altitude, and the inability of the plants from higher altitude (3310 and $3330 \mathrm{~m}$ a. s. 1.) to increase their leaf and root size when grown at a lower altitude, provide good evidence that local adaptation has occurred, inhibiting the plants from taking advantage of the conditions prevailing at $2950 \mathrm{~m}$ a. s. 1 .

3.4. Changes in Aboveground and Belowground Dry Matter and Seed Yield. The aboveground dry matter decreased with altitude increased while the belowground dry matter showed a reverse trend. Ecotypes from high altitude allocated significantly $(P<0.05)$ greater dry matter yield to roots than those adapted to low and mid altitudes. Aboveground dry matter yield allocation averaged $875 \mathrm{~kg} / \mathrm{ha}$ at the lowest altitude, nearly twice the value of the plants from the highest altitude. It was observed that ecotypes from lower altitudes allocated more dry matter to the stems of plants than those from higher altitudes. Total dry matter (combined root and shoot dry matter) values for the four ecotypes showed that there was a reduction with each increase in original elevation (Table 1), while root: shoot ratios also increased, providing a clear indication that the total abiotic stress increased with altitude, as root:shoot ratio increases with nearly every 


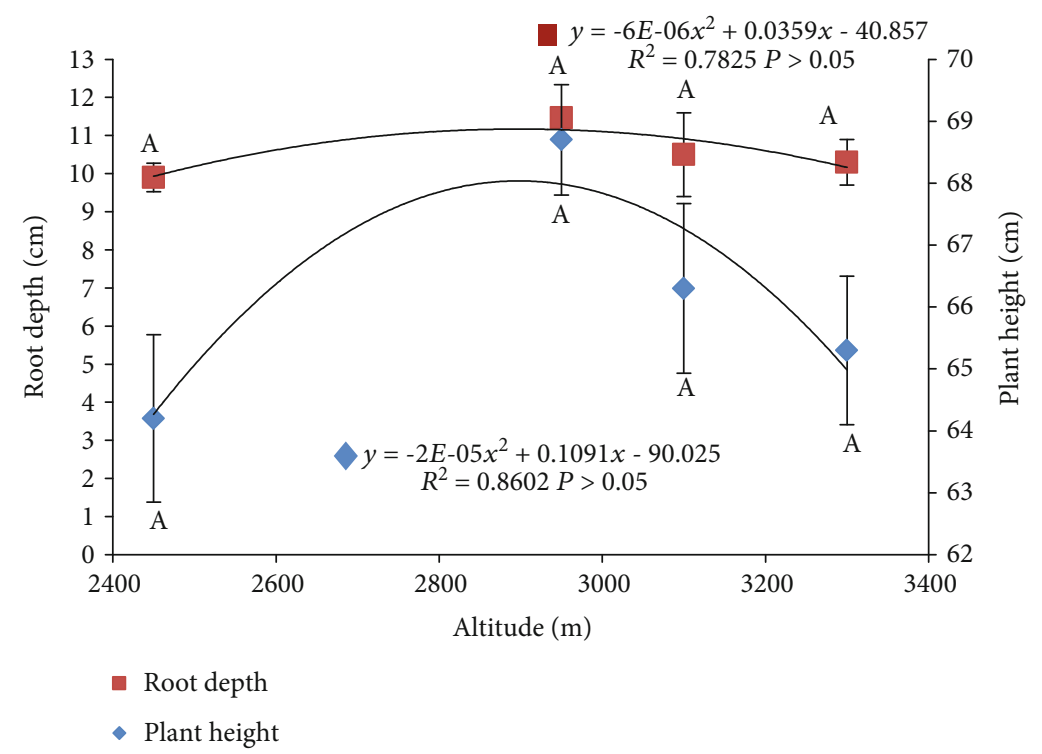

Figure 2: Plant and root depth of four E. nutans populations from different altitudes in the northeastern Tibetan Plateau, when grown at a single elevation of $2950 \mathrm{~m}$ a. s. l. Values are shown as the mean \pm SE of three replicated. Different letters indicate that the mean values are significantly different among the treatments $(P=0.05)$.

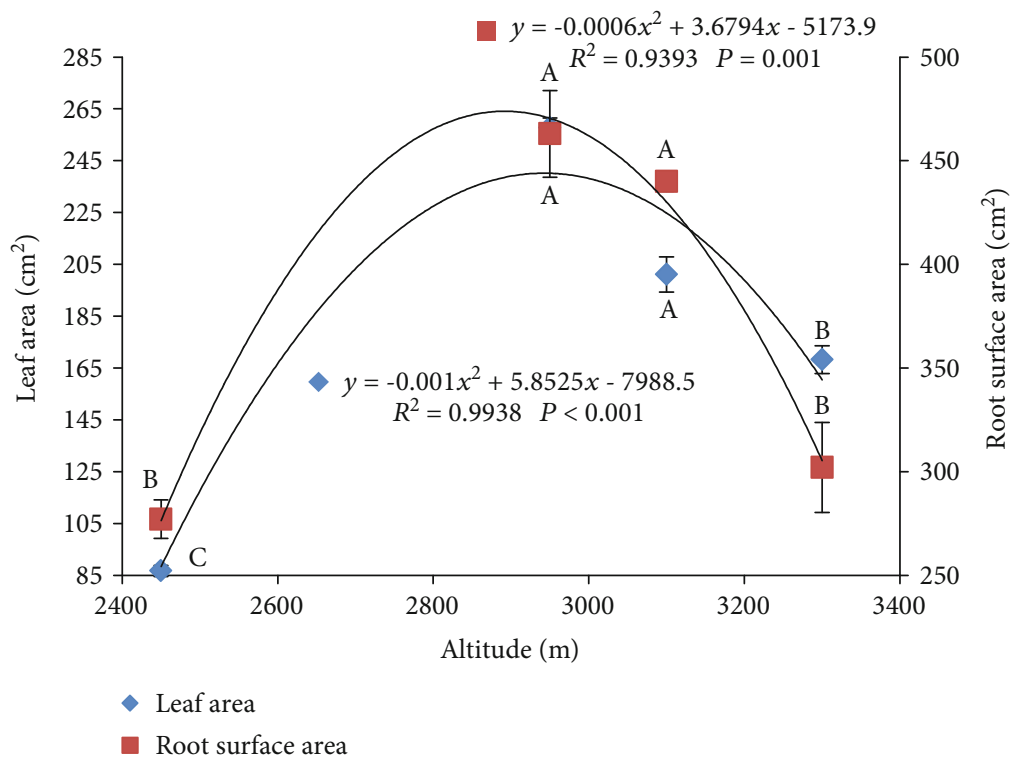

Figure 3: Changes in the plant and root area of four E. nutans populations from different altitudes in the northeastern Tibetan Plateau. Values are shown as the mean \pm SE of three replicated. Different letters indicate that the mean values are significantly different among the treatments $(P=0.05)$.

abiotic stress. The plants selected from, and grown at $2450 \mathrm{~m}$ a. s. 1., were the largest in total weight, while the plants from the $2950 \mathrm{~m}$ a. s. 1. were only slightly smaller, but they partitioned more of their assimilates into roots or seeds and less into dry matter. Plants from $3000 \mathrm{~m}$ a. s. l. were consistently smaller in every respect and were not able to take advantage of the milder conditions when grown at $2950 \mathrm{~m}$ a. s. 1 .

Seed yield of plants from 2450 to $2950 \mathrm{~m}$ a. s. l. increased $22.4 \mathrm{~kg} / \mathrm{ha}$ and then decreased markedly and reached a minimum at the $3300 \mathrm{~m}(46.2 \mathrm{~kg} / \mathrm{ha})$, with the seed yields from
3100 and $3300 \mathrm{~m}$ a. s. 1. being significantly lower than either of the lower altitudes. While seed production of the $2450 \mathrm{~m}$ a. s. l. ecotype was somewhat restricted by being grown at the higher elevation, the lack of capacity of the 3100 and $3300 \mathrm{~m}$ ecotypes to exploit the more favourable growing conditions at $2950 \mathrm{~m}$ a. s. l. again indicates that substantial local adaptation has taken place.

3.5. Soluble Sugar and Starch Content. Soluble sugar and starch content all showed significant differences in the leaves 


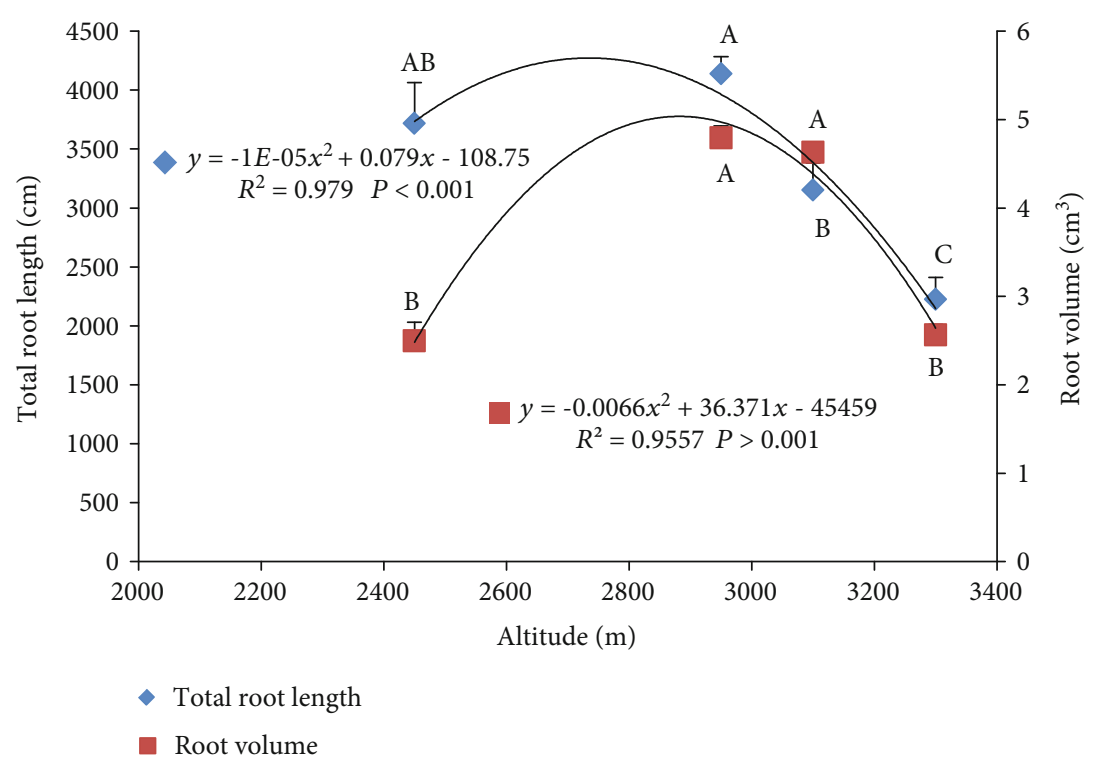

Figure 4: Changes in the total root length and root volume of four E. nutans populations from different altitudes in the northeastern Tibetan Plateau. Values are shown as the mean \pm SE of three replicated. Different letters indicate that the mean values are significantly different among the treatments $(P=0.05)$.

TABLE 1: Aboveground, belowground, and total dry matter with root: shoot ratios at flowering and seed yield at $80 \%$ maturity for four different populations of E. nutans.

\begin{tabular}{|c|c|c|c|c|c|}
\hline Altitude (m) & $\begin{array}{l}\text { Aboveground dry } \\
\text { matter }\left(\mathrm{kg} \mathrm{hm}^{-2}\right)\end{array}$ & $\begin{array}{l}\text { Belowground dry } \\
\text { matter }\left(\mathrm{kg} \mathrm{hm}^{-2}\right)\end{array}$ & $\begin{array}{l}\text { Root : shoot } \\
\text { ratio }\end{array}$ & $\begin{array}{c}\text { Total plant } \\
\text { weight }\left(\mathrm{kg} \mathrm{hm}^{-2}\right)\end{array}$ & $\begin{array}{l}\text { Seed yield } \\
\left(\mathrm{kg} \mathrm{hm}^{-2}\right)\end{array}$ \\
\hline 2450 & $875 \pm 32.4^{\mathrm{a}}$ & $283.8 \pm 24.5^{\mathrm{b}}$ & $0.32 \pm 0.04^{\mathrm{c}}$ & $1159 \pm 8.9^{\mathrm{a}}$ & $85.6 \pm 3.07^{\mathrm{b}}$ \\
\hline 2950 & $707 \pm 28.3^{\mathrm{b}}$ & $343.8 \pm 4.09^{\mathrm{a}}$ & $0.49 \pm 0.03^{\mathrm{b}}$ & $1051 \pm 24.3^{\mathrm{b}}$ & $108 \pm 2.71^{\mathrm{a}}$ \\
\hline 3100 & $640 \pm 16.7^{\mathrm{bc}}$ & $347.3 \pm 14.2^{\mathrm{a}}$ & $0.55 \pm 0.03^{\mathrm{ab}}$ & $987 \pm 22.7^{\mathrm{bc}}$ & $67 \pm 3.18^{c}$ \\
\hline 3300 & $588 \pm 8.1^{c}$ & $364.5 \pm 20.2^{\mathrm{a}}$ & $0.62 \pm 0.03^{\mathrm{a}}$ & $953 \pm 28.3^{c}$ & $46.2 \pm 3.61^{\mathrm{d}}$ \\
\hline
\end{tabular}

TABLE 2: Soluble sugar and starch content of seedlings along the altitude gradients.

\begin{tabular}{lcccc}
\hline \multirow{2}{*}{ Altitude $(\mathrm{m})$} & \multicolumn{2}{c}{ Soluble sugar content $(\%)$} & \multicolumn{2}{c}{ Starch content (\%) } \\
& Aboveground & Belowground & Aboveground & Belowground \\
\hline 2450 & $0.694 \pm 0.02^{\mathrm{b}}$ & $0.025 \pm 0.0^{\mathrm{b}}$ & $0.035 \pm 0.0^{\mathrm{b}}$ & $0.021 \pm 0.0^{\mathrm{a}}$ \\
2950 & $0.918 \pm 0.01^{\mathrm{a}}$ & $0.043 \pm 0.0^{\mathrm{ab}}$ & $0.043 \pm 0.0^{\mathrm{a}}$ & $0.035 \pm 0.0^{\mathrm{b}}$ \\
3100 & $0.889 \pm 0.01^{\mathrm{a}}$ & $0.053 \pm 0.0^{\mathrm{a}}$ & $0.034 \pm 0.0^{\mathrm{b}}$ & $0.033 \pm 0.0^{\mathrm{b}}$ \\
3300 & $0.736 \pm 0.02^{\mathrm{b}}$ & $0.032 \pm 0.0^{\mathrm{b}}$ & $0.031 \pm 0.0^{\mathrm{b}}$ & $0.014 \pm 0.0^{\mathrm{c}}$ \\
\hline
\end{tabular}

and roots of plants derived from different altitudes. The soluble sugars followed the similar parabolic curve to the root and shoot morphological traits increasing first with altitude from 2450 to $2950 \mathrm{~m}$ a. s. 1. and then decreasing (Table 2). Soluble sugars of belowground roots reached the highest value at $3100 \mathrm{~m}$ a. s. 1. The aboveground starch contents were only marginally different from plants originating from $2950 \mathrm{~m}$ a. s. 1., but the belowground starch contents of plants from the highest and lowest altitudes were significantly less than those from the intermediate altitudes.
3.6. Total $C$ and Total $N$ Concentration and the Ratios of $C: N$. Table 3 shows that aboveground $\mathrm{C}$ contents were not significantly different except in plants derived from $2450 \mathrm{~m}$, although plants from 3100 and $3300 \mathrm{~m}$ a. s. l. had numerically greater $\mathrm{C}$ contents. The root $\mathrm{C}$ was similarly higher in the plants from the lowest altitude. There were no significant differences in root $\mathrm{C}$ content among ecotypes from high altitudes. The plants derived from lowest altitude had a significantly lower aboveground nitrogen $(\mathrm{N})$ content and higher belowground $\mathrm{N}$ content than the other ecotypes. The aboveground $\mathrm{C}: \mathrm{N}$ increased as the altitude increased, 
TABLE 3: Total C content, $\mathrm{N}$ content, and $\mathrm{C}: \mathrm{N}$ of seedlings along the elevation gradients.

\begin{tabular}{|c|c|c|c|c|c|c|}
\hline \multirow{2}{*}{ Altitude (m) } & \multicolumn{2}{|c|}{ Carbon content $(\%)$} & \multicolumn{2}{|c|}{ Nitrogen content $(\%)$} & \multirow{2}{*}{$\begin{array}{c}\mathrm{C}: \mathrm{N} \\
\text { Aboveground }\end{array}$} & \multirow{2}{*}{$\begin{array}{c}\mathrm{C}: \mathrm{N} \\
\text { Belowground }\end{array}$} \\
\hline & Aboveground & Belowground & Aboveground & Belowground & & \\
\hline 2450 & $23.9 \pm 1.4^{\mathrm{b}}$ & $48.57 \pm 4.69^{\mathrm{a}}$ & $1.28 \pm 0.01^{\mathrm{b}}$ & $2.23 \pm 0.06^{\mathrm{a}}$ & $18.7 \pm 1.2^{\mathrm{bc}}$ & $21.78 \pm 1.5^{\mathrm{a}}$ \\
\hline 2950 & $39.28 \pm 3.6^{\mathrm{a}}$ & $33.06 \pm 1.98^{\mathrm{b}}$ & $1.61 \pm 0.05^{\mathrm{a}}$ & $2.11 \pm 0.08^{\mathrm{ab}}$ & $24.4 \pm 1.49^{\mathrm{bc}}$ & $15.67 \pm 0.8^{\mathrm{b}}$ \\
\hline 3100 & $49.5 \pm 4.88^{\mathrm{a}}$ & $28.4 \pm 3.14^{\mathrm{b}}$ & $1.65 \pm 0.04^{\mathrm{a}}$ & $1.87 \pm 0.07^{\mathrm{b}}$ & $30 \pm 3.2^{\mathrm{ab}}$ & $15.2 \pm 1.2^{\mathrm{b}}$ \\
\hline 3300 & $47.9 \pm 1.52^{\mathrm{a}}$ & $30.8 \pm 2.45^{\mathrm{b}}$ & $1.55 \pm 0.04^{\mathrm{a}}$ & $2.05 \pm 0.10^{\mathrm{ab}}$ & $30.9 \pm 0.4^{\mathrm{a}}$ & $15 \pm 0.8^{\mathrm{b}}$ \\
\hline
\end{tabular}

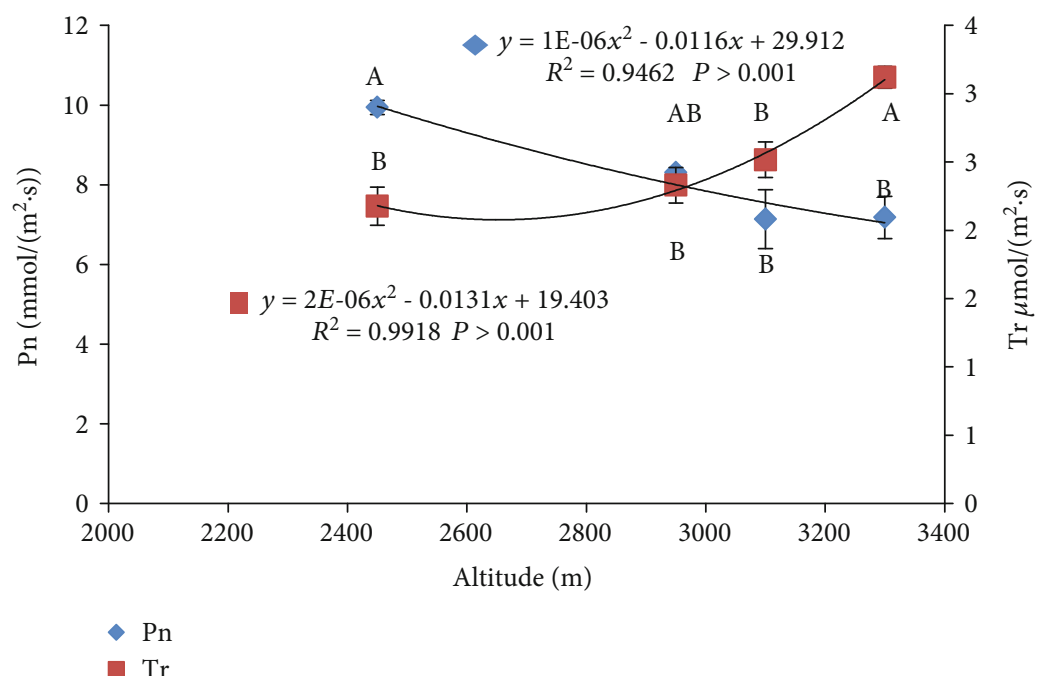

(a)

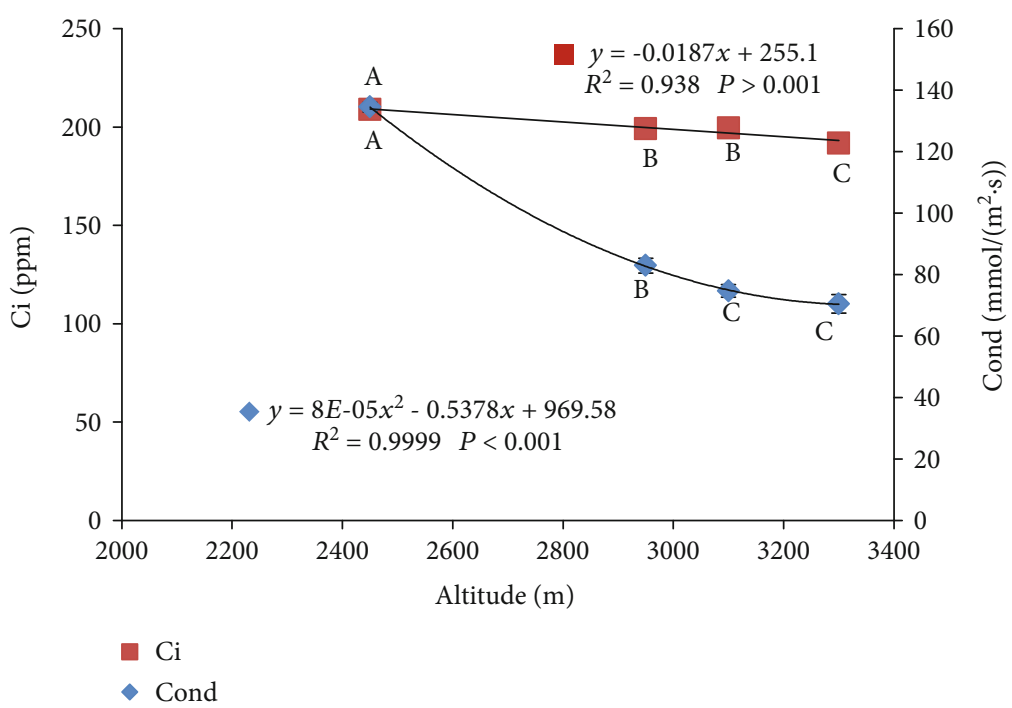

(b)

Figure 5: (a) Photosynthetic response (Pn-net photosynthetic rate) and transpiration (Tr). (b) Response of intercellular $\mathrm{CO}_{2}$ concentration (Ci) and stomatal conductance (Cond) measured on four E. nutans populations from different altitudes. Values are shown as the mean \pm SE of three replicated. Different letters indicate that the mean values are significantly different among the treatments $(P=0.05)$.

but the root $\mathrm{C}: \mathrm{N}$ ratio was only significantly different in the $2450 \mathrm{~m}$ a. s. l. ecotype.

3.7. Photosynthetic Parameters of Leaves of Four E. nutans Populations from Different Altitudes. Photosynthetic characteristics in leaves of the four ecotypes from different altitudes were measured during the period of maximum growth (the end of July, second year). The results (Figure 5) are the means of data collected between 8:30 am-17:30 pm during 25 July. They showed the photosynthetic rate $(\mathrm{Pn})$ and intercellular $\mathrm{CO}_{2}$ concentration $(\mathrm{Ci})$ responded in a similar manner to the shoot dry matter. Pn decreased as the altitude increased. 
The Pn of plants from $3300 \mathrm{~m}$ was $28 \%$ lower than those from $2450 \mathrm{~m}$ a. s. 1., but there was no significant difference among values of plants from 2950, 3100, and $3300 \mathrm{~m}$ a. s. 1 . However, $\operatorname{Tr}$ increased as the altitude from which the plants were derived increased. The $\operatorname{Tr}$ from $3300 \mathrm{~m}$ was $43 \%$ higher than that of $2450 \mathrm{~m}$ a. s. 1. (Figure 5(a)). By calculating the water use efficiency $(\mathrm{WUE}=\mathrm{Pn} / \mathrm{Tr})$, it was found the plant WUE gradually decreased from lower altitude to higher altitude. The Cond and $\mathrm{Ci}$ responses were highly correlated with the altitude of the original populations and decreased significantly as altitude increased (Figure 5(b)). The Ci and Cond from $3300 \mathrm{~m}$ were lower than that of from $2450 \mathrm{~m}$ a. s. 1 . $8 \%$ and $48 \%$, respectively.

\section{Discussion}

4.1. Variation in Morphological Traits of E. nutans with Altitude Gradient Migration. Altitude is an important ecological factor that affects population differentiation and genetic variation. The high altitude especially in the alpine region has a pronounced influence on the plants. Plants have obvious adaptation strategies by modifying their morphological and physiological attributes [30]. The long-term effects of environment on plants can alter their morphology, physiological function, and ecology $[31,32]$. Only those that adapt to their environment can survive well, while those that do not will gradually be eliminated from the local ecosystem. Therefore, morphological characterization of ecotypes provides useful information for evaluation of agronomic aptitude and development of new varieties [33].

In most alpine species, small stature is a genetic adaptation to low temperatures, and hence, they retain this feature when grown in a warm environment as low temperature affects the growth process and photosynthetic carbon gain [34]. In this experimental location, plant height, root depth, and root volume of $E$. nutans from different altitudes showed no significant change. These were the relatively conservative traits among the morphological traits measured along altitudinal gradients in an alpine region, similar to those described by Zhu's research [35]. However, ecotypes from $3300 \mathrm{~m}$ had larger leaf areas and root surface areas than those from $2450 \mathrm{~m}$ a. s. 1 . In the cold temperate zone, an increase in temperature reduces abiotic stress and improves the overall plant growth rate [36], especially affecting the photosynthetic and nutrient absorption processes. Our results are in line with other research findings for trees [37]. Furthermore, the plants derived from $2950 \mathrm{~m}$ a. s. 1 . and grown at the same altitude had the greatest morphological size in attributes such as plant height, root length, leaf area, total root length, and root volume. This indicated that local ecotypes performed better than the introduced plants from other altitudes because they were better adapted to local environmental conditions [38]. In addition, different ecotypes of the same species may adopt different survival strategies to adapt to the environmental stress [39]. For plants growing in the cold environments, for example, the leaf area and leaf size are normally small but the corresponding plant dry matter accumulation and net photosynthesis rate may be more profoundly affected [40]. The physiological measurements relating to photosyn- thesis taken at the period of fastest daily growth (prior to flowering) showed that the plants derived from 2950 and $3100 \mathrm{~m}$ a. s. l. were growing faster, which supports this interpretation. The plants from the highest altitude (3300 $\mathrm{m}$ a. s. 1.) were not able to adjust to the warmer growing conditions within a single generation, and the plants from the lowest altitude ( $2450 \mathrm{~m}$ a. s. 1.) were probably restricted by the lower temperatures they encountered at $2950 \mathrm{~m}$ a. s. 1. [41].

4.2. Effect of Altitude Migration on Material Accumulation and Distribution. Although the four ecotypes of the species E. nutans were generally similar in appearance and morphological characteristics, differences were observed in the dry matter characteristics, carbon, and nitrogen content. Plants from the lowest altitude maintained higher dry matter accumulation and seed yield than those adapted to $2950 \mathrm{~m}$ a. s. 1 . This is good evidence that there had been local adaptation to the conditions occurring at different altitudes [42]. We could expect that plants selected from the lowest altitude and grown at a higher altitude would not grow so fast because they were exposed to more cold, and that the plants from the higher altitudes grown at lower altitude would grow faster (and perhaps accumulate more belowground dry matter) and also through regulating physiological activity to adapt to the environment changes. When we compared (Table 1) the way the plants from different altitudes partitioned their assimilates, it was clear that the total amount of plant production (aboveground and belowground dry matter and seed yield) was significantly less in the plants from the higher altitudes, despite being grown at a more favourable (warmer) altitude, whereas the plants from the two lower altitudes had a similar total biomass but allocated their assimilates in different ways. The total amount of aboveground herbage was greatest in the plants from the lowest altitude (and probably if all ecotypes had been grown at $2450 \mathrm{~m}$ a. s. 1., these plants would have been largest overall). The plants originating from the low altitude may have had some differences in morphological and physiological characteristics that could possibly have been due to the results of natural selection not just the altitude factor [43]. However, overall, each ecotype largely kept its original characteristic when being transplanted to another altitude [44]. As we found a linear decrease in seed set with altitudinal origin, it is likely that the higher growth rates of plants from lower altitudes would be maintained in other growing sites.

4.3. Effect of Altitude Migration on Physiological Characteristics. Nonstructural carbohydrate (NSC) which mainly refers to the sugar and starch has a great influence on plant growth and adaptability [45]. NSC is the product of photosynthesis. Therefore, factors affecting photosynthesis will also affect NSC of plants [46]. When photosynthesis changes, the NSC may change a variety of ways that can be induced directly or indirectly by various environmental factors $[47,48]$. Previous studies have shown that photosynthetic capacity and plant $\mathrm{N}$ content may have a positive correlation while higher photosynthetic activity can increase $\mathrm{CO}_{2}$ assimilation so that NSC is also enhanced $[49,50]$. In our study, plants from the middle altitudes (2950 and 
$3100 \mathrm{~m}$ a. s. 1.) had higher soluble sugars, and root starch contents, in the typical parabolic response form, whereas the carbon and nitrogen contents and $\mathrm{C}: \mathrm{N}$ ratios were significantly different only in the plants derived from the lowest $(2450 \mathrm{~m}$ a. s. 1.) altitude suggesting they were partitioning their assimilates into structural components in different ways. The seedlings sourced from higher altitudes had better nitrogen utilization ability than those from lower altitudes. This suggests that ecotypes of Elymus nutans sourced from different altitudes may have beneficial attributes of adaptive value under the condition of future climate change.

We may postulate that plants from the lower elevations (below $3000 \mathrm{~m}$ a. s. 1.) are therefore most suited to being sown in situations where the amount of grass for yak feed is of most importance, whereas ecotypes that have developed at higher specific altitudes are most suited for use in rehabilitation programs aimed at repairing degraded natural grasslands that have suffered from erosion or overgrazing.

\section{Conclusions}

We can conclude that local adaptation has occurred in Elymus nutans growing naturally at different altitudes: these adaptations include changes in the size of the plants, the ratio of roots to shoots, the ratio of $\mathrm{C}: \mathrm{N}$, the total herbage and seed produced over the growing season, and the extent of the genetic by environment interaction (responsiveness) when grown at intermediate elevations. We suggest that ecotypes from the lower altitudes will be most productive for increasing grazing by yaks below $3000 \mathrm{~m}$ a. s. 1., but that locally adapted ecotypes should be used within their specific local habitats for ecological restoration of degraded grassland. Adaptation is the result of a long-term evolutionary process in concert with stress conditions. Further studies are needed to fully understand how altitude migration affects Elymus nutans growth on the Qinghai-Tibetan Plateau.

\section{Data Availability}

The data used to support the findings of this study are included within the article.

\section{Conflicts of Interest}

The authors declare there are no competing interests.

\section{Acknowledgments}

This work was supported by the National Natural Science Foundation of China (grant number 31660684), the Key Laboratory of Superior Forage Germplasm in the QinghaiTibetan Plateau (grant number 2020-ZJ-Y09), and the Earmarked Fund for China Agriculture Research System (grant number CARS-34). The authors are grateful to Changlin $\mathrm{Xu}$ for his help and valuable technical assistance and those students who were involved in part of the field and lab work.

\section{References}

[1] S. E. Sultan, "Phenotypic plasticity and plant adaptation," Acta Botanica Neerlandica, vol. 44, no. 4, pp. 363-383, 1995.

[2] P. Robakowski, P. Montpied, and E. Dreyer, "Plasticity of morphological and physiological traits in response to different levels of irradiance in seedlings of silver fir (Abies alba Mill)," Trees, vol. 17, no. 5, pp. 431-441, 2003.

[3] S. McIntyre, S. Lavorel, J. Landsberg, and T. D. A. Forbes, "Disturbance response in vegetation-towards a global perspective on functional traits," Journal of Vegetation Science, vol. 10, no. 5, pp. 621-630, 2009.

[4] F. J. Berli, R. Alonso, R. Bressan-Smith, and R. Bottini, "UV-B impairs growth and gas exchange in grapevines grown in high altitude," Physiologia Plantarum, vol. 149, no. 1, pp. 127-140, 2013.

[5] V. Dogra, P. S. Ahuja, and Y. Sreenivasulu, "Change in protein content during seed germination of a high altitude plant Podophyllum hexandrum Royle," Journal of Proteomics, vol. 78, no. 78, pp. 26-38, 2013.

[6] L. Pellissier, A. Espíndola, J. N. Pradervand et al., "A probabilistic approach to niche-based community models for spatial forecasts of assemblage properties and their uncertainties," Journal of Biogeography, vol. 40, no. 10, pp. 1939-1946, 2013.

[7] I. J. Wright, P. K. Groom, B. B. Lamont et al., "Short communication: leaf trait relationships in Australian plant species," Functional Plant Biology, vol. 31, no. 5, pp. 551-558, 2004.

[8] J. S. He, Z. Wang, X. Wang et al., "A test of the generality of leaf trait relationships on the Tibetan Plateau," New Phytologist, vol. 170, no. 4, pp. 835-848, 2006.

[9] A. D. Richardson, G. P. Berlyn, and T. G. Gregoire, "Spectral reflectance ofPicea rubens(Pinaceae) andAbies balsamea(Pinaceae) needles along an elevational gradient, Mt. Moosilauke, New Hampshire, USA," American Journal of Botany, vol. 88, no. 4, pp. 667-676, 2001.

[10] M. H. Li, J. Yang, and N. Kräuchi, "Growth responses of Picea abies and Larix decidua to elevation in subalpine areas of Tyrol, Austria," Canadian Journal of Forest Research, vol. 33, no. 4, pp. 653-662, 2003.

[11] Q.-q. Guo, H. E. Li, and W. H. Zhang, "Variations in leaf functional traits and physiological characteristics of Abies georgei var. smithii along the altitude gradient in the Southeastern Tibetan Plateau," Journal of Mountain Science, vol. 13, no. 10, pp. 1818-1828, 2016.

[12] C. C. Bresson, Y. Vitasse, A. Kremer, and S. Delzon, "To what extent is altitudinal variation of functional traits driven by genetic adaptation in European oak and beech?," Tree Physiology, vol. 31, no. 11, pp. 1164-1174, 2011.

[13] Z. Q. Cai, D. Y. Jiao, S. X. Tang, X. S. Dao, Y. B. Lei, and C. T. Cai, "Leaf photosynthesis, growth, and seed chemicals of Sacha Inchi plants cultivated along an altitude gradient," Crop Science, vol. 52, no. 4, pp. 1859-1867, 2012.

[14] J. A. Grytnes and O. R. Vetaas, "Species richness and altitude: a comparison between null models and interpolated plant species richness along the Himalayan altitudinal gradient, Nepal," The American Naturalist, vol. 159, no. 3, pp. 294-304, 2002.

[15] S. K. Schmidt, S. C. Reed, D. R. Nemergut et al., "The earliest stages of ecosystem succession in high-elevation (5000 metres above sea level), recently deglaciated soils," Proceedings of the 
Royal Society B: Biological Sciences, vol. 275, no. 1653, pp. 2793-2802, 2008.

[16] S. Ahmed, M. Ahmad, B. L. Swami, and S. Ikram, "A review on plants extract mediated synthesis of silver nanoparticles for antimicrobial applications: a green expertise," Journal of Advanced Research, vol. 7, no. 1, pp. 17-28, 2016.

[17] M. Hasanuzzaman, K. Nahar, M. Alam, R. Roychowdhury, and M. Fujita, "Physiological, biochemical, and molecular mechanisms of heat stress tolerance in plants," International Journal of Molecular Sciences, vol. 14, no. 5, pp. 9643-9684, 2013.

[18] A. S. Jump and J. Penuelas, "Running to stand still: adaptation and the response of plants to rapid climate change," Ecology Letters, vol. 8, no. 9, pp. 1010-1020, 2005.

[19] W. Xie, J. Zhang, X. Zhao, J. Zhang, and Y. Wang, "Siberian wild rye (Elymus sibiricus L.): Genetic diversity of germplasm determined using DNA fingerprinting and SCoT markers," Biochemical Systematics and Ecology, vol. 60, no. 60, pp. 186192, 2015.

[20] G. D. Zhou, Z. Y. Li, H. Y. Li, W. G. Shi, X. Y. Li, and L. Liu, "Research advances in germplasm resource of Elymus sibiricus," Pratacultural Science, vol. 28, no. 11, pp. 2026-2031, 2009.

[21] X. Y. Gu, Z. H. Guo, X. Q. Zhang, Y. H. Zhou, S. Q. Bai, and C. B. Zhang, "Genetic diversity of Elymus sibiricus germplasm resources revealed by SRAP markers," Acta Prataculturae Sinica, vol. 23, no. 3, pp. 205-216, 2014.

[22] X. Ma, S. Chen, X. Zhang, S. Bai, and C. Zhang, "Assessment of worldwide genetic diversity of Siberian wild rye (Elymus sibiricus L.) germplasm based on gliadin analysis," Molecules, vol. 17, no. 4, pp. 4424-4434, 2012.

[23] Y. Y. Zhao, D. J. Huang, Z. X. Mao, B. Nie, and H. Fu, "A study on forage nutritional quality of Elymus nutans from different populations in the Qinghai-Tibet Plateau," Acta Prataculturae Sinica, vol. 22, no. 1, pp. 38-45, 2013.

[24] J. H. Zheng, S. Y. Chen, Z. H. Chen, S. D. Li, and J. C. Zhong, "Assessment of genetic diversity of Elymus nutans in northwest plateau of Sichuan province using ISSR markers," Journal of Southwest University for Nationalities Natural Science Edition, vol. 40, no. 3, pp. 330-335, 2014.

[25] B. X. Xiao, M. Y. Yang, Q. Chen et al., "Study on relation between leaf anatomic structure and drought resistance of five forages in the northwest alpine grassland region of Sichuan," Prataculture and Animal Husbandry, vol. 209, no. 4, pp. 1-5, 2013.

[26] H. Q. Wang, Study on the Morphological Anatomy of Elymus L. Plants, [M.S. thesis], Chinese Academy of Agricultural Sciences Master Dissertation, Beijing, 2009.

[27] X. B. Yan, X. Wang, Y. X. Guo, and D. G. Zhang, "Biomass and feeding value dynamics of Elymus nutans pasture in cold alpine pastoral areas," Pratacultural Science, vol. 20, no. 11, pp. 14-18, 2003.

[28] S. D. Bao, Soil agrochemical analysis, China Agricultural Press, Beijing, China, 2000.

[29] M. Korn, W. Dossantos, M. Korn, and S. Ferreira, "Optimisation of focused-microwave assisted digestion procedure for Kjeldahl nitrogen determination in bean samples by factorial design and Doehlert design," Talanta, vol. 65, no. 3, pp. 710715, 2005.

[30] D. L. Royer, P. Wilf, D. A. Janesko, E. A. Kowalski, and D. L. Dilcher, "Correlations of climate and plant ecology to leaf size and shape: potential proxies for the fossil record," American Journal of Botany, vol. 92, no. 7, pp. 1141-1151, 2005.

[31] J. P. Gao, Y. H. Wang, and D. F. Chen, "Anatomical characteristics of leaf epidermis and vessel elements of Schisandra sphenanthera from different districts and their relationships to environmental factors," Acta Botanica Boreali-Occidentalia Sinica, vol. 23, no. 5, pp. 715-723, 2003.

[32] W. D. Lu, P. B. Xu, and X. Pu, "Summary of the situation for applying genetic resources from Elytrigia in Triticum aestivum breeding," Acta Prataculturae Sinica, vol. 16, no. 6, p. 136, 2007.

[33] S. A. Rao, K. E. P. Rao, M. H. Mengesha, and V. G. Reddy, "Morphological diversity in sorghum germplasm from India," Genetic Resources and Crop Evolution, vol. 43, no. 6, pp. 559567, 1996.

[34] C. Körner, "Plant adaptation to cold climates," F1000 Research, vol. 5, no. 5, 2016.

[35] W. H. Zhu, X. H. Zhang, and J. Z. Zhu, "Effect of different altitudes on the morphological traits of Phleum pretense," Pratacultural Science, vol. 36, no. 3, pp. 754-762, 2019.

[36] L. Rustad, J. Campbell, G. Marion et al., "A meta-analysis of the response of soil respiration, net nitrogen mineralization, and aboveground plant growth to experimental ecosystem warming," Oecologia, vol. 126, no. 4, pp. 543-562, 2001.

[37] L. Li, Ecophysiological Variation in Two Elevation Gradient Sources of Larix rechtii and Picea asperata Seedlings across an Elevation Gradient, [M.S. thesis], Shanxi Agricultural University, Shanxi, 2015.

[38] F. Montagnini, "Strategies for the recovery of degraded ecosystems: experiences from Latin America," Interciencia, vol. 26, no. 10, pp. 498-503, 2001.

[39] J. Qi, W. X. Cao, and W. H. Yan, "Phenotypic diversity and environment relations of wild Elymus populations," Acta Botanica Boreali-Occidentalia Sinica, vol. 33, no. 5, pp. 1027 1033, 2013.

[40] Y. H. Li, T. X. Luo, Q. Lu, X. Y. Tian, B. Wu, and H. H. Yang, "Comparisons of leaf traits among 17 major plant species in Shazhuyu sand control experimental station of Qinghai Province," Acta Ecologica Sinica, vol. 25, no. 5, pp. 994999, 2005.

[41] J.-d. He, J.-y. Xue, J. Gao, J.-n. Wang, and Y. Wu, “Adaptations of the floral characteristics and biomass allocation patterns of Gentiana hexaphylla to the altitudinal gradient of the eastern Qinghai-Tibet Plateau," Journal of Mountain Science, vol. 14, no. 8, pp. 1563-1576, 2017.

[42] A. H. Halbritter, R. Billeter, P. J. Edwards, and J. M. Alexander, "Local adaptation at range edges: comparing elevation and latitudinal gradients," Journal of Evolutionary Biology, vol. 28, no. 10, pp. 1849-1860, 2015.

[43] L. Gratani, "Plant phenotypic plasticity in response to environmental factors," Advances in Botany, vol. 2014, Article ID 208747, 17 pages, 2014.

[44] Y. Hautier, P. A. Niklaus, and A. Hector, "Competition for light causes plant biodiversity loss after eutrophication," Science, vol. 324, no. 5927, pp. 636-638, 2009.

[45] C. Körner, "Carbon limitation in trees," Journal of Ecology, vol. 91, no. 1, pp. 4-17, 2003.

[46] P. Millard, M. Sommerkorn, and G. A. Grelet, "Environmental change and carbon limitation in trees: a biochemical, ecophysiological and ecosystem appraisal," New Phytologist, vol. 175, no. 1, pp. 11-28, 2007. 
[47] M. C. Dietze, A. Sala, M. S. Carbone et al., "Nonstructural carbon in Woody plants," Annual Review of Plant Biology, vol. 65, no. 1, pp. 667-687, 2014.

[48] J. Martínez-Vilalta, A. Sala, D. Asensio et al., "Dynamics of non-structural carbohydrates in terrestrial plants: a global synthesis," Ecological Monographs, vol. 86, no. 4, pp. 495-516, 2016.

[49] S. -B. Zhang, H. Hu, K. Xu, and Z. . R. Li, "Photosynthetic performances of five Cypripedium species after transplanting," Photosynthetica, vol. 44, no. 3, pp. 425-432, 2006.

[50] Y. Zheng, F. Li, L. Hao et al., "Elevated $\mathrm{CO}_{2}$ concentration induces photosynthetic down-regulation with changes in leaf structure, non-structural carbohydrates and nitrogen content of soybean," BMC Plant Biology, vol. 19, no. 1, p. 255, 2019. 


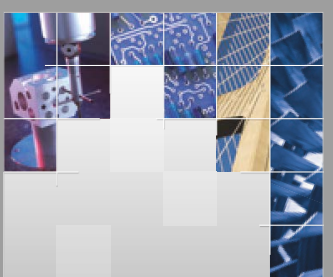

\section{Enfincering}
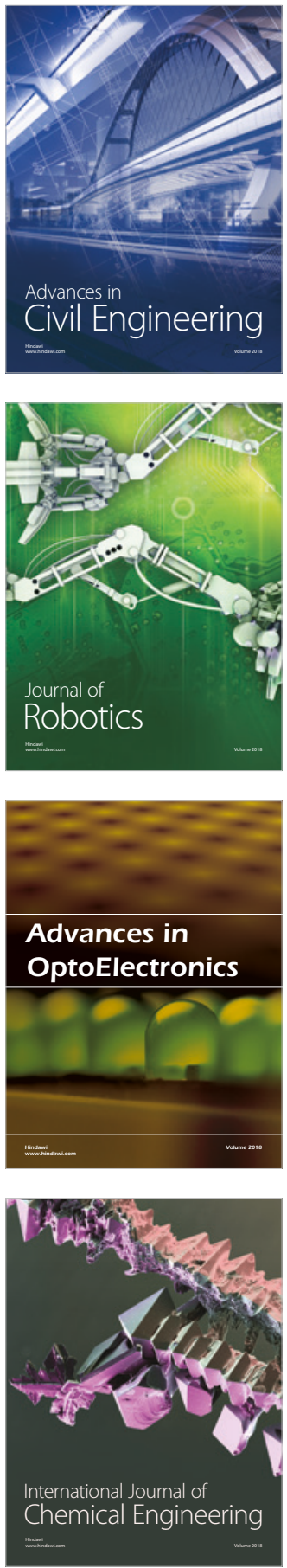

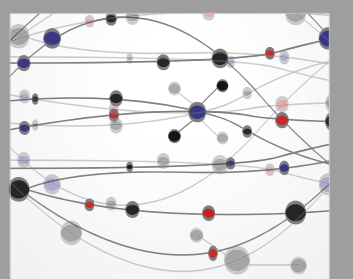

\section{Rotating \\ Machinery}

The Scientific World Journal

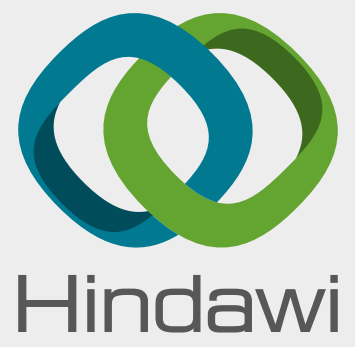

Submit your manuscripts at

www.hindawi.com
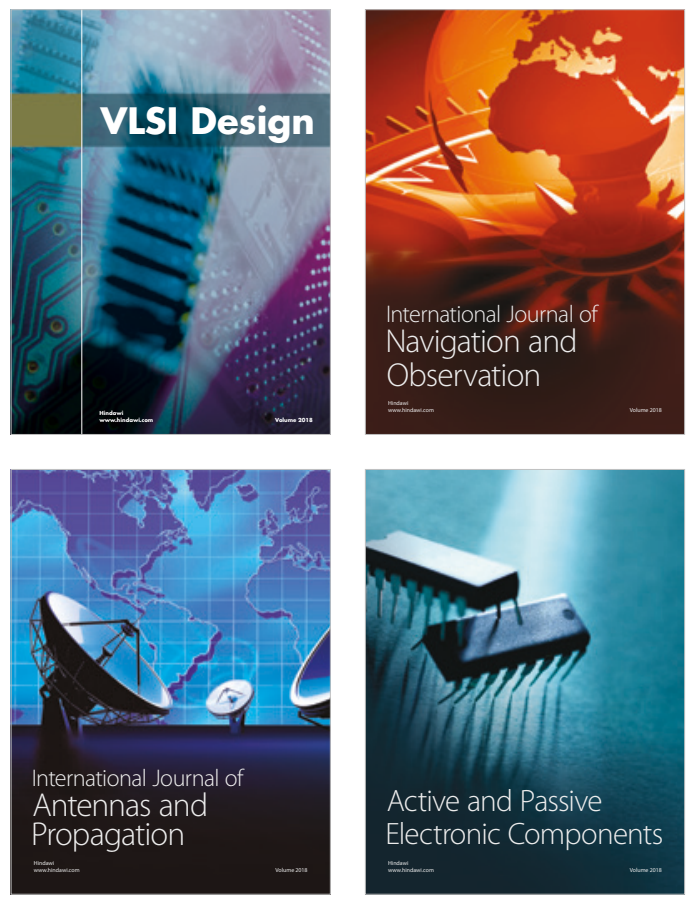
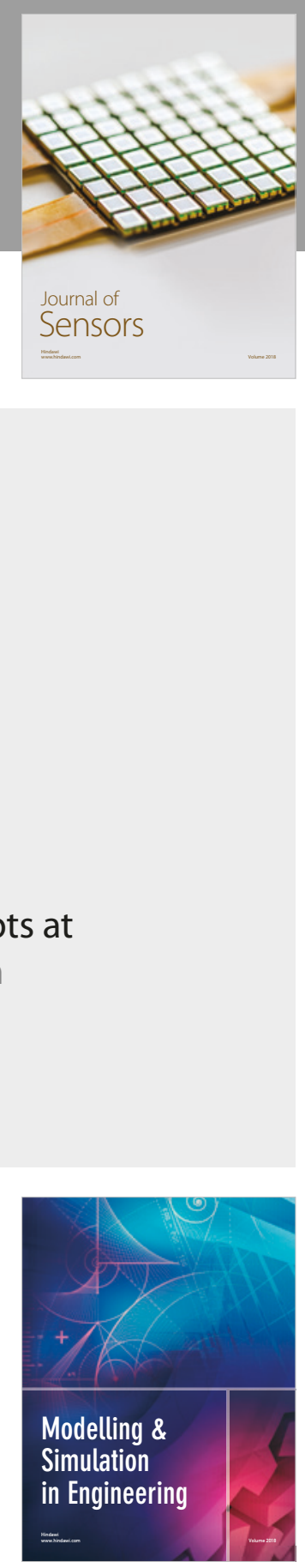

\section{Advances \\ Multimedia}
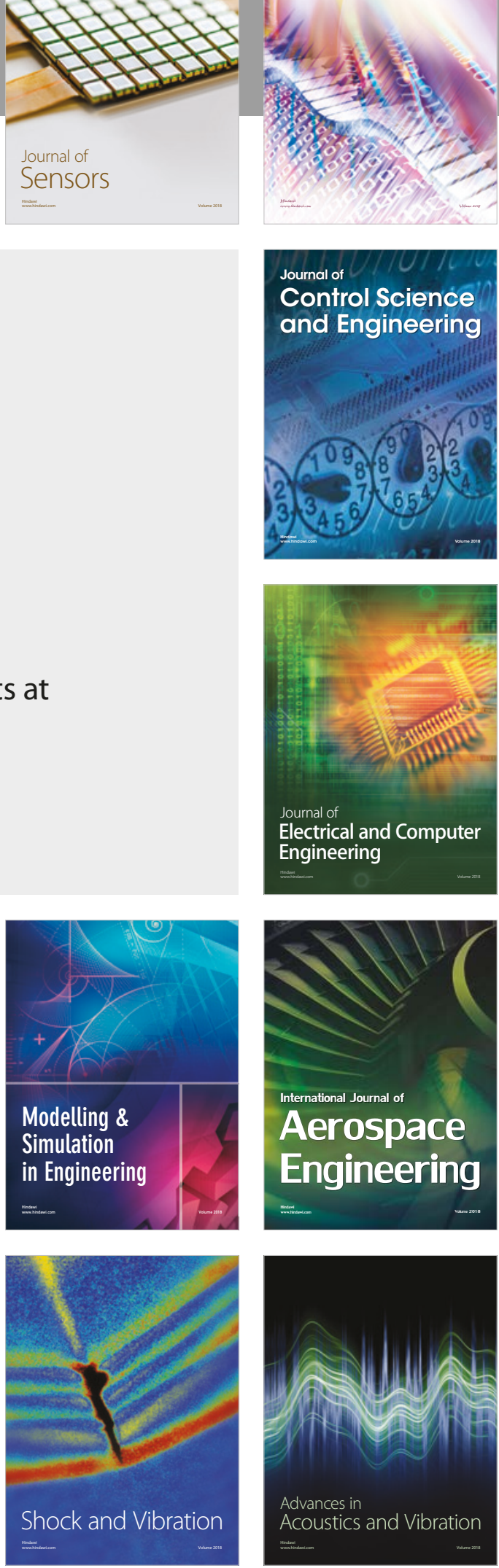